\title{
Incidence of penicillin tolerance among blood culture isolates of Streptococcus sanguis, 1987-88
}

\author{
P A James, S E J Young, D G White
}

\begin{abstract}
Laboratories that reported isolations of Streptococcus sanguis from blood cultures to the Communicable Disease Surveillance Centre (CDSC) Colindale were requested to submit strains to Bath Public Health Laboratory to allow the prevalence of penicillin tolerance within different biotypes of this species to be studied. One hundred and fifty one Streptococcus spp were received from 78 United Kingdom laboratories in one year. Strains were identified using the API 20 Strep, and minimum inhibitory concentrations (MICs) of penicillin were determined using the spiral gradient plate method. Penicillin tolerance was detected by spraying $\beta$-lactamase over inoculated gradient plates, reincubating for $\mathbf{4 8}$ hours and counting the number of surviving organisms represented by colonies. There were 57 different API identification profiles encountered in the survey. Most $S$ sanguis $I / 1$ strains were penicillin tolerant, most $S$ sanguis II strains were non-tolerant. The overall geometric mean MIC of penicillin was considerably lower for $\mathcal{S}$ sanguis $1 / 1$ than for all other biotypes. The distribution of biotypes and the geometric mean MIC of penicillin for each biotype were not significantly different for infective endocarditis strains than for all strains tested, suggesting little or no association between penicillin tolerance and the seeding of endocardium. When the reactions obtained using API 20 Strep were compared with a recent taxonomic study of viridans streptococci, 22 of $38 \mathrm{~S}$ sanguis $I / 1$ strains could be reclassified as $S$ gordonii; all these strains were penicillin tolerant. Such reclassification would allow likely penicillin tolerant strains to be predicted.
\end{abstract}

Penicillin tolerance was first described by Tomasz in 1970 in a laboratory mutant of Streptococcus pneumoniae. ${ }^{1}$ It has been defined as a minimun bactericidal:minimum inhibitory concentration ratio of $>32,{ }^{2}$ and although this definition has been criticised, ${ }^{3}$ it has been used extensively to differentiate tolerant from non-tolerant organisms. There are conflicting reports of the incidence of penicillin tolerance in streptococci, ${ }^{4}$ though the irreproducibility of conventional minimum inhibitory concentration (MIC) and minimum bactericidal (MBC) methods, particularly for streptococci, ${ }^{5}$ due to various technical factors, ${ }^{6}$ probably account for such discrepancies.

The clinical importance of penicillin tolerance is still uncertain, though it is likely to be of more importance in deep-seated infections such as infective endocarditis, where the use of bactericidal antibiotics is essential for a favourable clinical response. ${ }^{4}$ There are numerous case reports of streptococcal infections, particularly infective endocarditis, in which penicillin tolerance has been proposed as a possible explanation for treatment failure or poor clinical response. ${ }^{7-17}$

Streptococcus spp accounted for $4.4 \%$ of significant positive blood cultures reported to the Communicable Diseases Surveillance Centre (CDSC) from April 1987 to March 1988. Streptococcus spp account for more than $60 \%$ of cases of infective endocarditis, ${ }^{18}$ of which $S$ sanguis is the most frequently isolated species. $^{19}$

Because of the importance of $S$ sanguis in infective endocarditis, a study was undertaken to establish the incidence of penicillin tolerance in this species. We report several interesting findings relating to certain biotypes of $S$ sanguis. Because $S$ mitis is taxonomically very close to $S$ sanguis II, ${ }^{20}$ organisms identified as $S$ mitis were included in the study.

\section{Methods}

Laboratories reporting isolations of $S$ sanguis from blood cultures to the CDSC between April 1987 and March 1988 were requested to forward isolates to Bath Public Health Laboratory together with brief clinical details. On receipt, cultures were checked for purity and then stored at $-70^{\circ} \mathrm{C}$ in glycerol broth. On completion of the collection, all organisms were recovered from $-70^{\circ} \mathrm{C}$ and subcultured several times on blood agar plates incubated at $37^{\circ} \mathrm{C}$ in $7 \%$ carbon dioxide. Each isolate was identified using the API 20 Strep (API, bioMèrieux) in accordance with the manufacturer's instructions.

The API 20 Strep kits consist of plastic strips each with 20 microtubes containing substrates for detection of biochemical reactions in the following order: acetoin production (VP); hippurate hydrolysis and aesculin hydrolysis; production of pyrrolidonylarylamidase, $\alpha$-galactoside, $\beta$-glucuronidase, $\beta$ galactosidase, alkaline phosphatase, leucine arylamidase, and arginine dihydrolase; acidification of ribose, L-arabinose, mannitol, sor-

\author{
Correspondence to: \\ Mr P A James \\ Accepted for publication \\ 6 September 1990 \\ Disease Surveillance \\ Centre, Colindale, \\ London \\ S E J Young
}


Table 1 Blood culture isolations of viridans streptococci (laboratory reports to CDSC April 1987-March 1988)

\begin{tabular}{|c|c|c|c|}
\hline Organism & Total number & $\begin{array}{l}\text { With infect } \\
\text { number }\end{array}$ & $\begin{array}{l}\text { e endocarditis } \\
\text { (\%) }\end{array}$ \\
\hline $\begin{array}{l}S \text { milleri } \\
\text { Streptococcus group F } \\
S \text { mitis (mitior) } \\
S \text { mutans } \\
S \text { salivarius } \\
S \text { sanguis } \\
\alpha \text { and non-haemolytic streptococci } \\
\text { Total }\end{array}$ & $\begin{array}{r}203 \\
15 \\
194 \\
28 \\
65 \\
375 \\
196 \\
1076\end{array}$ & $\begin{array}{r}17 \\
2 \\
51 \\
22 \\
21 \\
136 \\
46 \\
295\end{array}$ & $\begin{array}{r}(8 \cdot 7) \\
(26 \cdot 3) \\
(78 \cdot 6) \\
(32 \cdot 3) \\
(36 \cdot 3) \\
(23 \cdot 5) \\
(27 \cdot 4)\end{array}$ \\
\hline
\end{tabular}

Table 2 Distribution of biotypes of $S$ sanguis from blood culture isolates received for investigation

\begin{tabular}{llll}
\hline & All isolates & $\begin{array}{l}\text { Presumed } \\
\text { infective endocarditis }\end{array}$ & $\begin{array}{l}\text { Suspected } \\
\text { infective endocarditis }\end{array}$ \\
\hline S sanguis biotype I & 57 & 17 & 25 \\
$S$ sanguis biotype II & 67 & 19 & 21 \\
All $S$ sanguis & 124 & 36 & 46 \\
\hline
\end{tabular}

Table 3 Number of strains tolerant for each API profile obtained

\begin{tabular}{|c|c|c|c|c|}
\hline Identification & API profile & $\begin{array}{l}\text { Identification } \\
\%\end{array}$ & $\begin{array}{l}\text { No of } \\
\text { strains }\end{array}$ & $\begin{array}{l}\text { No of } \\
\text { tolerant } \\
\text { strains }\end{array}$ \\
\hline$S$ sanguis I & $\begin{array}{l}0041611 \\
0241441\end{array}$ & $\begin{array}{l}91 \cdot 8 \\
(*)\end{array}$ & $\begin{array}{l}1 \\
1\end{array}$ & $\begin{array}{l}1 \\
0\end{array}$ \\
\hline$S$ sanguis $\mathrm{I} / ?$ & $\begin{array}{l}0041451 \\
4241450\end{array}$ & $\begin{array}{l}81 \cdot 2 \\
90 \cdot 8\end{array}$ & $\begin{array}{l}1 \\
2\end{array}$ & $\begin{array}{l}0 \\
1\end{array}$ \\
\hline$S$ sanguis $\mathrm{I} / 1$ & $\begin{array}{l}0041410 \\
0041430 \\
0041630 \\
0061430 \\
0241050 \\
4040410 \\
4041410 \\
4041430 \\
4041630 \\
4060411 \\
4060430 \\
4061410 \\
4061430 \\
4061431 \\
4071410 \\
4261470\end{array}$ & $\begin{array}{l}89 \cdot 8 \\
98 \cdot 1 \\
79 \cdot 5 \\
97 \cdot 3 \\
71 \cdot 7 \\
87 \cdot 1 \\
99 \cdot 6 \\
99 \cdot 8 \\
87 \cdot 2 \\
95 \cdot 0 \\
98 \cdot 4 \\
96 \cdot 9 \\
99 \cdot 6 \\
98 \cdot 3 \\
98 \cdot 5 \\
72 \cdot 1\end{array}$ & $\begin{array}{r}1 \\
2 \\
1 \\
1 \\
1 \\
1 \\
1 \\
3 \\
1 \\
2 \\
1 \\
3 \\
17 \\
1 \\
1 \\
1\end{array}$ & $\begin{array}{l}1 \\
1 \\
1 \\
1 \\
0 \\
1 \\
0 \\
2 \\
1 \\
0 \\
1 \\
3 \\
17 \\
1 \\
1 \\
1\end{array}$ \\
\hline$S$ sanguis $I / 2$ & $\begin{array}{l}0041631 \\
0041671 \\
0241251 \\
0241471 \\
0241651 \\
4241451 \\
4241470 \\
4241471 \\
4241650 \\
4241670 \\
4241671\end{array}$ & $\begin{array}{l}79 \cdot 3 \\
99 \cdot 0 \\
98 \cdot 1 \\
75 \cdot 4 \\
99 \cdot 5 \\
93 \cdot 7 \\
77 \cdot 5 \\
94 \cdot 9 \\
99 \cdot 3 \\
99 \cdot 6 \\
99 \cdot 9\end{array}$ & $\begin{array}{l}1 \\
1 \\
1 \\
1 \\
1 \\
4 \\
1 \\
1 \\
1 \\
1 \\
1\end{array}$ & $\begin{array}{ll}0 & (1) \\
0 & (1) \\
0 & (1) \\
1 & \\
1 & \\
3 \\
0 \\
1 \\
1 \\
1 \\
1\end{array}$ \\
\hline$S$ sanguis II & $\begin{array}{l}0240440 \\
0240441 \\
0240451 \\
0241441 \\
0241451 \\
0242451 \\
0251441 \\
0260440 \\
0260441 \\
0260451 \\
0260460 \\
0260641 \\
0261440 \\
0261441 \\
0261450 \\
0261461 \\
0270450\end{array}$ & $\begin{array}{l}\left({ }^{\star}\right) \\
97 \cdot 8 \\
97 \cdot 8 \\
\left({ }^{\star}\right) \\
\left({ }^{\star}\right) \\
83 \cdot 4 \\
\left({ }^{\star}\right) \\
99 \cdot 6 \\
99 \cdot 9 \\
99 \cdot 3 \\
\left({ }^{\star}\right) \\
98 \cdot 1 \\
96 \cdot 8 \\
98 \cdot 4 \\
73 \cdot 7 \\
72 \cdot 1 \\
98 \cdot 6\end{array}$ & $\begin{array}{r}1 \\
5 \\
1 \\
1 \\
1 \\
1 \\
1 \\
2 \\
26 \\
12 \\
1 \\
2 \\
7 \\
3 \\
1 \\
1 \\
1\end{array}$ & $\begin{array}{l}0 \\
0 \\
0 \\
0 \\
0 \\
0 \\
0 \\
0 \\
0 \\
0 \\
0 \\
0 \\
0 \\
3 \\
1 \\
1 \\
1 \\
0 \\
0 \\
0\end{array}$ \\
\hline$S$ mitis & $\begin{array}{l}0040400 \\
0040401 \\
0040420 \\
0041400 \\
0041401 \\
0041421 \\
0060401 \\
0060410 \\
0060411\end{array}$ & $\begin{array}{l}87 \cdot 1 \\
98 \cdot 2 \\
89 \cdot 3 \\
(\star) \\
84 \cdot 4 \\
\left({ }^{\star}\right) \\
99 \cdot 1 \\
79 \cdot 1 \\
91 \cdot 2\end{array}$ & $\begin{array}{l}1 \\
3 \\
1 \\
2 \\
3 \\
1 \\
1 \\
2 \\
2\end{array}$ & $\begin{array}{l}0 \\
0 \\
0 \\
0 \\
1 \\
1 \\
0 \\
1 \\
1\end{array}$ \\
\hline
\end{tabular}

( ${ }^{\star}$ Identification confirmed by API bioMèrieux laboratories.

Numbers in parentheses indicate strains that were tolerant only in the stationary phase of growth. bitol, lactose, trehalose, inulin, raffinose, starch and glycogen. The final test used was the production of haemolysis on blood agar. A seven digit profile number was obtained by assigning each group of three tests a numerical value of 1,2 , and 4 sequentially and scoring positive tests within each group. Profile numbers obtained after 24 hour incubation were translated to organism identifications using APILAB software version $1 \cdot 3$. The identification for organisms that gave "identification percentages" of below $70 \%$ was confirmed by API bioMèrieux laboratories using API $50 \mathrm{CH}$.

Minimum inhibitory concentrations of penicillin were determined using the Spiral Gradient Endpoint (SGE) method, which we have previously shown to be a reproducible method for MIC determinations with Streptococcus spp. ${ }^{5}$ Penicillin gradients covering a range of concentrations from $120 \mathrm{mg} / 1$ to $0.001 \mathrm{mg} / 1$ over two plates were established using a spiral plater (Spiral Instruments) on $140 \mathrm{~mm}$ Petri dishes containing Iso-Sensitest agar (Oxoid) with $1 \%$ lysed horse blood to a depth of $3.3 \mathrm{~mm}$. Starting concentrations used to establish the gradients were 19500 $\mathrm{mg} / \mathrm{l}$ and $47 \mathrm{mg} / \mathrm{l}$.

Overnight BHI (Oxoid) broth cultures (stationary phase) were diluted 10-fold in warm BHI broth and incubated further for one to two hours at $37^{\circ} \mathrm{C}$ to obtain log-phase cultures. Each set of gradient plates was inoculated with five different clinical isolates in both $\log$ and stationary phases of growth from the periphery to within $20 \mathrm{~mm}$ of the centre using sterile cotton-tipped swabs. Tolerant (San 1303) and non-tolerant (San 2131) control strains with known MICs to penicillin were included on every plate. The plates were incubated at $37^{\circ} \mathrm{C}$ in $7 \%$ carbon dioxide for 24 hours. After incubation the endpoints of growth were marked on the reverse of the plate with a felt-tipped pen. The plates were then sprayed with $1.0 \mathrm{ml}$ of $50 \mathrm{U} / \mathrm{ml}$ broad spectrum $\beta$-lactamase (Porton Products) and reincubated for 48 hours after which the plates were examined for regrowth of inhibited cells. Greater than 10 colonies above the MIC endpoints was taken to be indicative of penicillin tolerance.

Results

The number of blood culture isolates and the number of cases of infective endocarditis reported to the CDSC during the study period are shown in table 1. A total of 151 Streptococcus strains were received from 78 United Kingdom laboratories during the study, 124 identified as $S$ sanguis, 16 as $S$ mitis, and the remaining 11 were various other species. The distribution of $S$ sanguis biotypes from presumed and suspected cases of infective endocarditis and other bacteraemias is shown in table 2. In this series the distribution of $S$ sanguis biotypes I and II, overall, and from cases of infective endocarditis was roughly equal. 


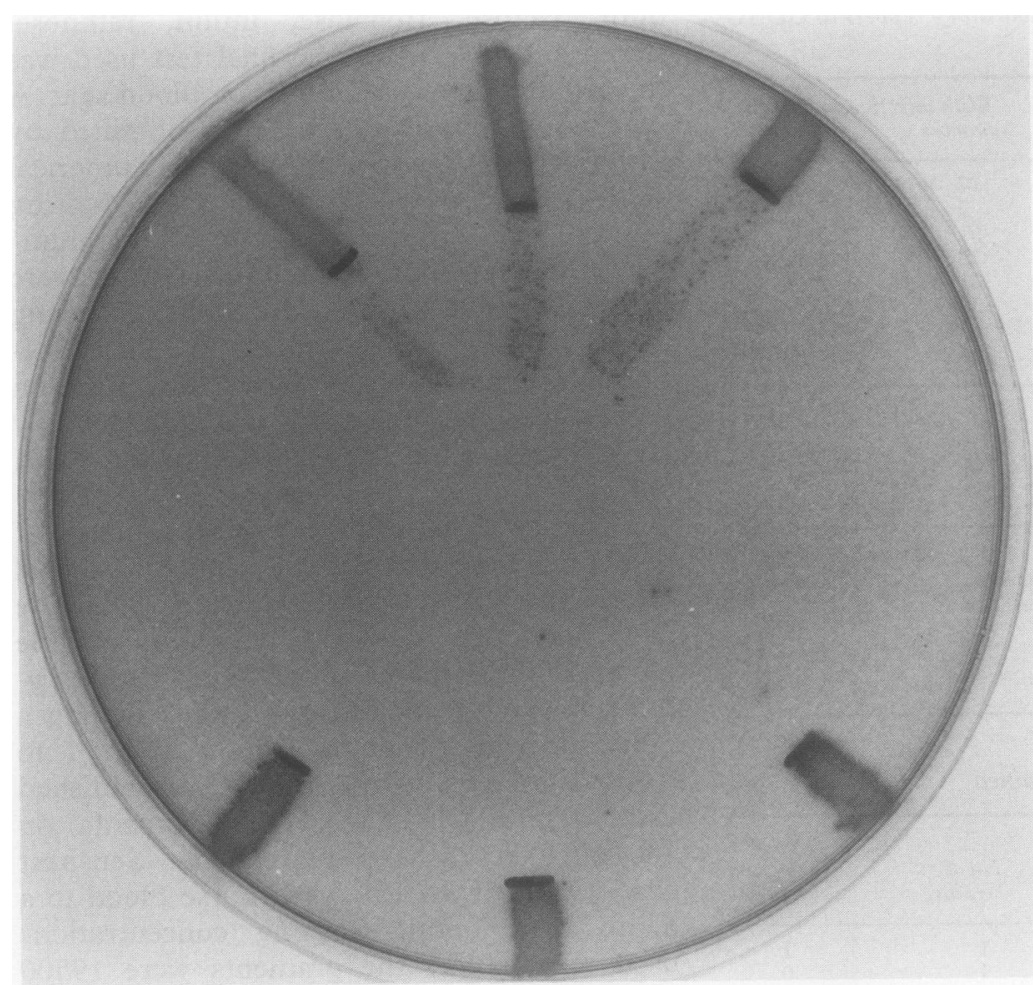

Spiral gradient endpoint plate inoculated with three tolerant $\mathrm{S}$ sanguis I strains (top) and three non-tolerant $\mathrm{S}$ sanguis II strains (bottom). The plate was incubated at $37^{\circ} \mathrm{C}$ for 24 hours, the endpoints of growth marked, and the plate sprayed with $\beta$-lactamase and reincubated for 48 hours. The tolerant strains show regrowth of colonies beyond the MIC endpoints.

Table 4 Incidence of penicillin tolerance in organisms tested, with geometric mean MICs for tolerant and non-tolerant strains

\begin{tabular}{lllll}
\hline \multirow{2}{*}{$\begin{array}{l}\text { Organism } \\
\text { No tolerant } /\end{array}$} & \multicolumn{3}{l}{ Geometric mean $M I C$ of penicillin $(\mathrm{mg} / \mathrm{l})$} \\
\cline { 3 - 5 } & No tested & Tolerant & Non-tolerant & All \\
\hline S sanguis I/1 & $32 / 38$ & 0.0066 & 0.12 & 0.0073 \\
S sanguis I/2 & $9 / 14$ & 0.025 & 0.020 & 0.023 \\
S sanguis II & $5 / 67$ & 0.066 & 0.023 & 0.026 \\
All S sanguis & $48 / 124$ & 0.011 & 0.023 & 0.018 \\
S mitis & $4 / 16$ & 0.034 & 0.052 & 0.047 \\
\hline
\end{tabular}

Fifty seven different API profiles were encountered in the study (table 3 ). $S$ sanguis I/ 1 strains with API profiles ranging from 4060430-4241450 (24 strains) all gave tolerant responses to penicillin in the logarithmic phase of growth whereas $S$ sanguis II strains with API profiles ranging from 0242451-0260641 (45 strains) all gave non-tolerant responses. This association of tolerance with biotype I strains and non-tolerance with biotype II strains was highly significant $\left(\chi^{2}\right.$ test, $\left.\mathrm{p}>0.001\right)$. The figure shows a gradient plate illustrating the different responses of tolerant $S$ sanguis I/1 strains and non-tolerant $S$ sanguis II strains to the killing action of penicillin.

All strains that were tolerant in the logarithmic phase of growth were also tolerant in the stationary phase of growth; 11 strains were tolerant only in the stationary phase (table 3 ). There was no significant difference (all within the equivalent of one doubling dilution) between MICs in the two phases of growth.

The geometric mean MIC of penicillin for tolerant and non-tolerant $S$ sanguis biotypes and the number of tolerant strains in each biotype is shown in table 4 . Both control organisms which were included on every plate $(\mathrm{n}=37)$ gave consistent results. The tolerant control ( $S$ sanguis $\mathrm{I} / 3$ ) had a geometric mean MIC of $0.0056 \mathrm{mg} / 1$ with a range (2 SD) of $0.0036-0.0086 \mathrm{mg} / \mathrm{l}$, and the non-tolerant control ( $S$ sanguis II) had a geometric mean MIC of $0.0643 \mathrm{mg} / 1$ with a range (2 SD) of 0.0283 $0 \cdot 1461 \mathrm{mg} / \mathrm{l}$.

Tolerant strains of $S$ sanguis $\mathrm{I} / 1$ (which accounted for the majority of tolerant strains) had significantly lower MICs to penicillin than did any other biotype. Conversely, the six nontolerant strains of $S$ sanguis $\mathrm{I} / 1$ had significantly higher MICs than any other biotype. There was no significant difference (all within the equivalent of a doubling dilution) between the overall pattern of geometric MICs (table 4) and geometric MICs of strains from infective endocarditis.

\section{Discussion}

The prevalence of different Streptococcus spp involved in infective endocarditis was similar to that reported in other British and American studies. ${ }^{19}$ It has been suggested that biotype II strains may have greater avidity for endocardium. ${ }^{21}$ We could not show a significant difference in the distribution of biotype II strains from cases of infective endocarditis when compared with the overall distribution $\left(\chi^{2}\right.$ test, $p>$ $0.05)$. This observation also indicates that penicillin tolerance is not a factor in establishing the initial infection.

The clustering of tolerant and non-tolerant strains to ranges of API identification profiles for $S$ sanguis I and $S$ sanguis II, respectively, was particularly interesting and suggests that penicillin tolerance is a trait closely associated with certain biotypes and not easily (if at all) transferable to other strains of Streptococcus spp. The mode of peptidoglycan cross-linking in these biotypes is believed to be different, ${ }^{22}$ thus the outcome of penicillin exposure of these biotypes may be a consequence of their different peptidoglycan structures. The difference in cell wall structure may also account for the different geometric mean MICs of penicillin between $S$ sanguis $\mathrm{I} / 1$ and $S$ sanguis II strains. It is perhaps not surprising that it has recently been suggested that $S$ sanguis $\mathrm{I} / 1$ should constitute a separate species on the basis of DNA homology studies. ${ }^{20}$ If the reactions obtained with API 20 Strep are compared with those in a recent taxonomic study of viridans streptococci by Kilian $e t a l,{ }^{23}$ then most strains identified as $S$ sanguis II would become $S$ mitis, and 22 of the 38 strains of $S$ sanguis $\mathrm{I} / 1$ (profiles $4061410-4071410$ in table 1) would probably be included in a proposed new species, $S$ gordonii. What is important is that all the strains that we tested which were consistent with the description of $S$ gordonii were penicillin tolerant. It is presently not known whether a patient's response to infection is influenced by the biotype of the infecting strain, though studies using the rabbit model of infective endocarditis provide evidence that 
penicillin tolerance is an important factor in the response to antimicrobial chemotherapy. ${ }^{24-27}$ The species and biovar of the infecting strain may therefore have important implications for the course of the disease in man. These implications may become more apparent as the classification of the viridans streptococci is improved.

We thank all the laboratories that submitted strains to enable the study and API bioMerieux for confirming the identity of equivocal strains and supplying API 20 S strips.

1 Tomasz A, Albino A, Zanati E. Multiple antibiotic resistance in a bacterium with suppressed autolytic system. tance in a bacterium with

2 Sabath LD, Laverdiere M, Wheeler N, Blazevic D, Wilkinson BJ. A new type of penicillin resistance of Staphylococcus aureus. Lancet 1977;i:443-7.

3 Meylan PR, Francioli P, Glauser P. Discrepancies between $\mathrm{MBC}$ and actual killing of viridans group streptococci by cell-wall-active antibiotics. Antimicrob Agents Chemother 1986;29:418-23.

4 Handwerger S, Tomasz A. Antibiotic tolerance among clinical isolates of bacteria. Rev Infect Dis 1985;7:368-86.

5 James PA. Comparison of four methods for the determination of MIC and MBC of penicillin for viridans streptococci and the implications for penicillin tolerance. cocci and the implications for penicill
$J$ Antimicrob Chemother 1990;25:209-16.

6 Sherris JC. Problems in in-vitro determination of antibiotic tolerance in clinical isolates. Antimicrob Agents Chemother 1986;30:633-7.

7 Allen JL, Sprunt K. Discrepancy between minimum inhibitory and minimum bactericidal concentrations of penicillin for group A and group B $\beta$-hemolytic streptococci. J Pediatr 1978;93:69-71

8 Broughton DD, Mitchell WG, Grossman M, Hadley WK, Cohen MS. Recurrence of group B streptococcal infection. J Pediatr 1976;89:183-5.

9 Dagan R, Ferne M. Association of penicillin-tolerant streptococci with epidemics of streptococcal pharyngitis in closed communities. Eur J Clin Microbiol Infect Dis 1989 8:629-31.

10 Fung JC, Gadbaw JJ, Donta ST, Tilton RC. Infective endocarditis due to penicillin-tolerant Streptococcus bovis. Diagn Microbiol Infect Dis 1986;5:171-6.

11 Grahn E, Holm SE, Roos K. Penicillin tolerance in betastreptococci isolated from patients with tonsillitis. Scand J Infect Dis 1987;19:421-6.
12 Griffiths LR, Green HT. Paradoxical effect of penicillin in vivo. J Antimicrob Chemother 1985;15:507-8.

13 Portnoy D, Prentis J, Richards GK. Penicillin tolerance of human isolates of group $\mathrm{C}$ streptococci. Antimicrob Agents Chemother 1981;20:235-8.

14 Savitch CB, Barry AL, Hoeprich PD. Infective endocarditis caused by Streptococcus bovis resistant to the lethal effect of penicillin G. Arch Intern Med 1978;138:931-4.

15 Schauf V, Deveikis A, Riff L, Serota A. Antibiotic-killing kinetics of group B streptococci. J Pediatr 1976;89:194-8.

16 Smith TD, Huskins CW, Kim KS, Kaplan EL. Efficacy of $\beta$-lactamase-resistant penicillin and influence of penicillin tolerance in eradicating streptococci from the pharyn after failure of penicillin therapy for group A streptococca pharyngitis. J Pediatr 1987;110:777-82.

17 Streinbreder P. Serious infection in an adult due to penicillin-tolerant group B Streptococcus. Arch Intern Med 1981;141:1714-5.

18 Baylis R, Clarke C, Oakley CM, Somerville W, Whitfield AGW, Young SEJ. The microbiology and pathogenesis of infective endocarditis. Br Heart J 1983;50:513-9.

19 Scheld MW. Therapy of streptococcal endocarditis: correlation of animal and clinical studies. J Antimicrob Chemother tion of animal and

20 Coykendall AL. Classification and identification of the viridans streptococci. Clin Microbiol Rev 1989;2:315-28.

21 Coykendall AL, Efstratiou A, Colman G. Streptococcus sanguis genotypes in endocarditis. Abstracts of the Annual Meeting of the American Society for Microbiology. Washington DC: ASM, 1986:B37, 30.

22 Schleifer $\mathrm{KH}$, Kandler O. Peptidoglycan types of bacterial cell walls and their taxonomic implications. Bact Rev 1972;36:407-77.

23 Kilian M, Mikkelsen L, Henrichsen J. Taxonomic study of viridans streptococci: Descriptions of Streptococcus gordonii sp. nov. and amended descriptions of Streptococcus sanguis (White and Niven 1946), Streptococcus oralis (Bridge and Sneath 1982), and Streptococcus mitis (Andrews and Horder 1906). Int J Syst Bacteriol 1989; 39:471-84.

24 Pulliman L, Inokuchi S, Hadley KW, Mills J. Penicillin tolerance of viridans streptococci delays sterilization of vegetations in experimental endocarditis. Clin Res 1980; 28:45A.

25 Brennan RO, Durack DT. Therapeutic significance of penicillin tolerance in experimental streptococcal endocarditis. Antimicrob Agents Chemother 1983;23: 273-7.

26 Hess J, Dankert J, Durack D. Significance of penicillin tolerance in-vivo: Prevention of experimental Streptococcus sanguis endocarditis. J Antimicrob Chemother cus sanguis $1983 ; 11: 555-64$

$27 \mathrm{Kim}$ KS, Bayer AS. Significance of in-vitro penicillin tolerance in experimental enterococcal endocarditis. J Antimicrob Chemother 1987;19:475-85. 